Original Article

\title{
Approaches for improving the toileting problems of hemiplegic stroke patients with poor standing balance
}

\author{
Yuji Koike ${ }^{1)^{*}}$, Koshi Sumigawa ${ }^{1)}$, Shuhei Koeda ${ }^{1)}$, Miyuki Shinna ${ }^{2)}$, Haruka Fukushi ${ }^{3)}$, \\ Takahiro Tsuis ${ }^{3)}$, Chisaya Hara ${ }^{2)}$, Hitoshi Tsushima ${ }^{1)}$ \\ 1) Hirosaki University Graduate School of Health Sciences: 66-1 Honcho, Hirosaki, Aomori 036-8564, \\ Japan \\ 2) Tokiwakai Hospital, Japan \\ 3) Geriatric Health Services Facility, Meiseien, Japan
}

\begin{abstract}
Purpose] Our objective was to evaluate the residual dynamic and static functionality in the sitting position of hemiplegic stroke patients who require help to pull their lower garments up and down during toileting. [Subjects and Methods] The subjects were 11 hemiplegic patients. We gathered data on the patients' motor paralysis, sensory capacity, lower extremity muscle strength, trunk control, ability to roll and sit up from a lying position, sitting balance, and ability to pull the lower garments up and down. We then compared 2 groups: those able to pull the lower garments up and down independently while standing (the "independent group"), and those who were unable to do so (the "non-independent group"). [Results] Though the non-independent group had severely and significantly reduced trunk control and abilities as a whole, there was no significant difference from the independent group in static and dynamic sitting balance. [Conclusion] We conclude that, to enable hemiplegic patients with poor standing balance to pull their lower garments up and down, it is necessary to do these maneuvers in a sitting, rather than a standing, position, or to develop garments that are easier to put on and take off.

Key words: Sitting position, Toileting approach, Stroke patients with poor standing balance
\end{abstract}

(This article was submitted Sep. 26, 2014, and was accepted Nov. 7, 2014)

\section{INTRODUCTION}

When stroke occurs, it is often accompanied by problems with toileting that necessitate toileting care. Toileting care places a physical and psychological burden on both the caregiver and the recipient of care ${ }^{1)}$, and together with bathing help, it ranks among the most burdensome of care tasks. It can also present obstacles that make the discharge of patients to their homes unfeasible ${ }^{2-4)}$. Therefore, the establishment of toileting independence is a critically important issue for hemiplegic stroke patients.

Toileting comprises various movements ${ }^{5}$. Of these movements, pulling the lower garments up and pulling the lower garments down are the most difficult ${ }^{6,7)}$. To resolve the problem of impaired ability to perform these movements, many occupational therapists conduct rehabilitation ${ }^{8}$. However, many hemiplegic patients remain unable to pull the lower garments up and down while standing, even after receiving training. The approach used by occupational therapists aims to improve the degree of independence with which patients can perform activities of daily living (ADL), and different

*Corresponding author. Yuji Koike (E-mail: ot_koike@ hirosaki-u.ac.jp)

(C)2015 The Society of Physical Therapy Science. Published by IPEC Inc This is an open-access article distributed under the terms of the Creative Commons Attribution Non-Commercial No Derivatives (by-ncnd) License $<$ http://creativecommons.org/licenses/by-nc-nd/3.0/> . authors within occupational therapy emphasize the importance of focusing on adaptive approaches which depend on the patient's degree of independence when the patients are assessed rather than focusing on impairments ${ }^{9,10)}$. Given the poor results of such rehabilitation, we think that there is a need to reconsider the practices used to improve hemiplegic patients' ability to perform these maneuvers.

Hemiplegic patients who remain unable to pull the lower garments up and down while standing after receiving training often have poor standing balance ${ }^{11)}$. Pulling the lower garments up and down in a sitting position has been proposed as a method suitable for such patients ${ }^{12)}$. However, many of the studies of training to improve the ability to perform these movements have involved efforts to improve motor paralysis or poor standing balance and little research has focused on using patients' residual functionality and abilities to teach them to pull their lower garments up and down while sitting, rather than standing, or by adjusting the patient's environment ${ }^{13)}$. One possible reason for this is that hemiplegic patients with poor standing balance may not have sufficient residual capacity to pull the lower garments up and down while sitting. We therefore aimed to elucidate residual dynamic and static functionality in the sitting position of hemiplegic patients in order to find ways of performing these maneuvers that would suit the capacity of those with poor standing balance. 


\section{SUBJECTS AND METHODS}

\section{Subjects}

Hemiplegic stroke patients who were either residents of a geriatric health services facility or ambulatory rehabilitation users were enrolled in this study. We obtained written informed consent to participation in this study from each subject. The inclusion criteria were as follows: hemiplegic patients who had suffered an initial cerebral infarction, cerebral hemorrhage, or subarachnoid hemorrhage and were able to sit without upper extremity support. Eleven such patients were included as study subjects. Patients meeting any of the following criteria were excluded: unstable vital signs; difficulty following instructions because of conditions such as disturbance of consciousness or severe aphasia; impaired communication ability because of impairment of motor or speech function; or concurrent conditions such as severe ataxia, dementia, higher brain function disorder, or orthopedic disorders.

\section{Methods}

Patient characteristics were evaluated by collecting the data on: age, gender, type of stroke, complications, time since stroke, and side affected by the stroke from the patients' medical records.

Ability to pull the lower garments up and down while standing was assessed using the Toileting section of the Functional Independence Measure (FIM) $)^{5}$. However, the Toileting section of the FIM includes not only pulling the lower garments up and down but also perineal hygiene. For this study we excluded perineal hygiene from the scope of the evaluation.

Motor paralysis of the upper and lower extremity and fingers were evaluated using the Brunnstrom Stage $\left.{ }^{14}\right)(\mathrm{Br}$. stage). The Br. stage rates the degree of motor paralysis on a 6 -step scale from I to VI.

We evaluated the sensory capacity of the upper and lower extremity and fingers by comparing surface and deep sensation on the affected and unaffected sides. We rated the degree of sensation on a 3-step scale: normal, hypoesthesia, or anesthesia.

Lower extremity muscle strength on the unaffected side was measured as knee extension muscle strength with a hand-held dynamometer ( $\mu$ tasF-1, Anima Corp; Tokyo, Japan). The patients sat on the edge of a platform adjusted so that the lower legs were hanging down. The sensor was fixed to the anterior surface of the distal lower leg and then connected to the supporting leg of the platform, behind the lower leg, via a harness. At the time of measurement, to prevent the sensor pad from shifting position, the tester manually maintained the position of the pad. The patients were instructed to sit with the trunk kept vertical with both arms folded in front, and to perform isometric knee extension with maximum effort for about $3 \mathrm{~s}$. Measurements were done twice, with ample rest between them. The highest measurement was divided by the patient's body weight to calculate the muscle strength in $\mathrm{kgf} / \mathrm{kg}$.

Trunk control was evaluated using the Trunk Control Test (TCT) ${ }^{15}$, which has been validated and is easy to use. The subtests of the TCT consist of 4 items: rolling to the weak side, rolling to the strong side, balance in the sitting position, and sitting up from lying down. These items are rated on a 3-step scale, with 0 points for "Unable to do", 12 points for "Able to do with non-muscular help", and 25 points for "Normal". The scores for these subtests are totaled to calculate a total TCT score which ranges from 0 to 100 . The higher the score, the better the patient's trunk control is.

Dynamic sitting balance was evaluated using the Functional Reach Test (FRT) ${ }^{16}$ ). The sitting FRT has been tested by Tyson et al. ${ }^{17)}$ and found to be reliable and valid. In the starting position, the hips and knees were bent at 90 degrees of flexion, with the shoulder joint on the unaffected side also at 90 degrees of flexion. The tester instructed the patient to reach as far forward as possible with the fingertips along a yardstick fixed at the level of the patient's acromion on the unaffected side. The measurement was performed twice, and the largest measurement was used in the analysis.

Static sitting balance was evaluated as the TCT subtest; balance in the sitting position.

To discover the residual functionality and abilities of hemiplegic stroke patients who were unable to pull their lower garments up and down independently while standing, the 11 patients were allocated to 2 groups: those who could do this task independently (the independent group) and those who could not (the non-independent group). The results of the two groups were then compared. Patients with scores of 7 or 6 in the Toileting section of the FIM for pulling the lower garments up and down were placed in the independent group, and patients with scores of 5 or lower were placed in the non-independent group.

Statistical analysis was performed using the MannWhitney U-test to compare data for age, time since stroke, knee extension muscle strength on the unaffected side, total TCT score, sitting FRT, and TCT subtest scores. The $\chi^{2}$ test was used to compare gender, type of stroke, complications, side of stroke, Br. stage, and sensory ability. SPSS Statistics 17.0 (Tokyo, Japan) was used as the software for statistical analysis, and significance was accepted in both tests at values of $\mathrm{p}<0.05$.

This study was approved by the Committee of Medical Ethics of Hirosaki University Graduate School of Medicine, Hirosaki, Japan (approval number 2012-276), and the Ethics Committee of Tokiwakai Medical Corporation.

\section{RESULTS}

The patients' characteristics are shown in Table 1. Most patients had Br. stage II in the upper extremity, I in the fingers, and III in the lower extremity. Many patients had a sensory level rated as hypoesthesia in each region (upper extremity, fingers, and lower extremity). As a result of our evaluation of the patients' ability to pull the lower garments up and down, 5 were placed in the independent group and 6 were placed in the non-independent group.

Table 2 compares the characteristics of the independent and non-independent groups. Compared with the independent group, the non-independent group had a significantly lower total TCT score $(\mathrm{p}<0.05)$, and showed significant differences in gender, and side of stroke $(\mathrm{p}<0.01)$. However, no significant differences were found in $\mathrm{Br}$. stage, sensory 
Table 1. Subject characteristics

\begin{tabular}{ll}
\hline & \multicolumn{1}{c}{ Subjects $(\mathrm{n}=11)$} \\
\hline Age (years) & $77.0(65.5-81.5)$ \\
Gender: male/female & $6 / 5$ \\
Type of stroke: infarction / hemorrhage / subarachnoid hemorrhage & $5 / 6 / 0$ \\
Complications: HT / DM / HL / other & $8 / 2 / 1 / 1$ \\
Time since stroke (months) & $61.0(17.5-115.5)$ \\
Side of stroke: right / left & $6 / 5$ \\
Br. stage & \\
Upper extremity: I / II / III / IV / V / VI & $0 / 7 / 2 / 1 / 0 / 1$ \\
Fingers: I / II / III / IV / V / VI & $6 / 2 / 0 / 2 / 0 / 1$ \\
Lower extremity: I / II / III / IV / V / VI & $0 / 1 / 7 / 2 / 0 / 1$ \\
Sensory capacity & \\
Upper extremity: normal / hypoesthesia / anesthesia & $3 / 7 / 1$ \\
Fingers: normal / hypoesthesia / anesthesia & $3 / 7 / 1$ \\
Lower extremity: normal / hypoesthesia / anesthesia & $4 / 6 / 1$ \\
Knee extension muscle strength in the lower extremity on unaffected side (kgf/kg) & $0.26(0.17-0.32)$ \\
Total TCT score & $61.0(49.0-87.0)$ \\
Sitting FRT (cm) & $26.0(22.0-30.0)$ \\
Pulling the lower garments up and down while standing: independent / non-independent & $5 / 6$ \\
\hline Values are medians (25-75\%). & \\
HT: hypertension; DM: diabetes mellitus; HL: hyperlipidemia; Br. stage: Brunnstrom stage; TCT: trunk control test; \\
FRT: functional reach test
\end{tabular}

Table 2. Comparison of characteristics of the independent and non-independent groups

\begin{tabular}{|c|c|c|}
\hline & $\begin{array}{l}\text { Independent group } \\
(\mathrm{n}=5)\end{array}$ & $\begin{array}{l}\text { Non-independent group } \\
(\mathrm{n}=6)\end{array}$ \\
\hline Age (years) ${ }^{\dagger}$ & $65.0(62.0-68.0)$ & $80.0(77.5-81.8)$ \\
\hline Gender: male/female ${ }^{\dagger \dagger}$ & $5 / 0$ & $1 / 5^{* *}$ \\
\hline 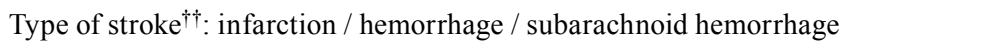 & $1 / 4 / 0$ & $4 / 2 / 0$ \\
\hline Complications $^{\dagger \dagger}$ : HT / DM / HL / other & $4 / 1 / 0 / 1$ & $4 / 1 / 1 / 0$ \\
\hline Time since stroke (months) ${ }^{\dagger}$ & $20.0(15.0-61.0)$ & $114.5(69.0-129.3)$ \\
\hline Side of stroke: right / left ${ }^{\dagger \dagger}$ & $5 / 0$ & $1 / 5^{* *}$ \\
\hline \multicolumn{3}{|l|}{ Br. stage } \\
\hline Upper extremity ${ }^{\dagger \dagger}$ : I / II / III / IV / V / VI & $0 / 2 / 2 / 0 / 0 / 1$ & $0 / 5 / 0 / 1 / 0 / 0$ \\
\hline Fingers ${ }^{\dagger}:$ I / II / III / IV / V / VI & $2 / 2 / 0 / 0 / 0 / 1$ & $4 / 0 / 0 / 2 / 0 / 0$ \\
\hline Lower extremity ${ }^{\dagger \dagger}$ : I / II / III / IV / V / VI & $0 / 0 / 2 / 2 / 0 / 1$ & $0 / 1 / 5 / 0 / 0 / 0$ \\
\hline \multicolumn{3}{|l|}{ Sensory capacity } \\
\hline Upper extremity ${ }^{\dagger \dagger}$ : normal / hypoesthesia / anesthesia & $1 / 4 / 0$ & $2 / 3 / 1$ \\
\hline Finger $^{\dagger \dagger}$ : normal / hypoesthesia / anesthesia & $1 / 4 / 0$ & $2 / 3 / 1$ \\
\hline Lower extremity ${ }^{\dagger \dagger}$ : normal / hypoesthesia / anesthesia & $2 / 3 / 0$ & $2 / 3 / 1$ \\
\hline Knee extension muscle strength in lower extremity on unaffected side $(\mathrm{kgf} / \mathrm{kg}){ }^{\dagger}$ & $0.26(0.23-0.32)$ & $0.23(0.16-0.33)$ \\
\hline Total TCT score ${ }^{\dagger}$ & $100.0(74.0-100.0)$ & $49.0(49.0-58.0)^{*}$ \\
\hline 1. Rolling to the weak side ${ }^{\dagger}$ & $25.0(12.0-25.0)$ & $6.0(0.0-12.0)^{*}$ \\
\hline 2. Rolling to the strong side ${ }^{\dagger}$ & $25.0(25.0-25.0)$ & $12.0(12.0-12.0)^{*}$ \\
\hline 3. Balance in the sitting position [static balance $]^{\dagger}$ & $25.0(25.0-25.0)$ & $25.0(25.0-25.0)$ \\
\hline 4. Sitting up from a lying position ${ }^{\dagger}$ & $25.0(12.0-25.0)$ & $12.0(3.0-12.0)^{*}$ \\
\hline Sitting FRT $(\mathrm{cm})[\text { dynamic balance }]^{\dagger}$ & $26.0(23.0-37.0)$ & $24.5(21.5-26.8)$ \\
\hline
\end{tabular}

Values are medians $(25-75 \%)$.

HT: hypertension; DM: diabetes mellitus; HL: hyperlipidemia; Br. stage: Brunnstrom stage; TCT: trunk control test; FRT: functional reach test

${ }^{\dagger}$ : Mann-Whitney U-test; ${ }^{\dagger} \chi^{2}$ test; *: $\mathrm{p}<0.05,{ }^{* *}: \mathrm{p}<0.01$ 
capacity, knee extension muscle strength on the unaffected side, or sitting FRT. In the TCT subtest scores of the independent and non-independent groups, significantly more patients in the non-independent group than in the independent group had difficulty with rolling to the weak side, rolling to the strong side, and sitting up from lying down $(\mathrm{p}<0.05)$. However, all patients - even those in the non-independent group - were able to perform the balance in the sitting position task.

\section{DISCUSSION}

We determined that the ability to pull the lower garments up and down independently while standing is affected by factors such as trunk control and ability to roll and sit up, in addition to standing balance. This means that if trunk control such as the ability to roll and sit-up is impaired by stroke, it becomes difficult for a hemiplegic stroke patient to pull the lower garments up and down. Therefore, for functional independence in pulling the lower garments up and down, occupational therapists need to improve hemiplegic stroke patients' trunk control, e.g. the ability to roll and sit up. We found no significant difference in static and dynamic sitting balance between the non-independent and independent groups. Thus, the patients in the non-independent group had a level of sitting balance equivalent to that of the independent group. This result suggests that hemiplegic stroke patients who found pulling the lower garments up and down difficult in a standing position may have been able to do these maneuvers in a sitting position. Many authors have proposed pulling the lower garments up and down in a sitting position as a method suitable for hemiplegic patients with poor standing balance ${ }^{12)}$, but there have been few reports on making good use of residual functionality and abilities for this purpose ${ }^{13)}$ Nevertheless, pulling the lower garments up and down in a sitting position has reportedly led to independence in these maneuvers ${ }^{12}$ ). Our results demonstrate that many patients in the non-independent group had retained their sitting balance, suggesting that even those with poor standing balance do have the ability to pull the lower garments up and down independently in a sitting position.

In the current medical care environment, importance is placed on independence in the performance of ADL for the purposes of stroke rehabilitation ${ }^{18)}$. In addition, as stated above, different authors within occupational therapy emphasize the importance of focusing on adaptive approaches which depend on the patient's degree of independence when patients are assessed rather than focusing on impairments ${ }^{9,10)}$. It would seem that we need a change in perspective that considers approaches that suit the residual functionality and abilities of individual hemiplegic patients - such as the possibility of training in pulling the lower garments up and down while sitting in order to achieve independence in this maneuver. Enabling patients to achieve these maneuvers may help to alleviate the physical and psychological burdens on caregivers and recipients of care. It will also raise the possibility of discharging patients to their homes. Occupational therapists need to utilize approaches which make good use of the residual capacities of hemiplegic patients with poor standing balance.
The difficulties experienced by hemiplegic stroke patients with poor standing balance in pulling the lower garments up and down can be addressed by either changing the movement used (i.e. using a sitting, rather than standing, position) or developing garments that are easier to pull up and down. For the former, dynamic sitting balance is required, because patients need to move the trunk forwards, backwards, left, and right when performing this activity. Because we showed here that the non-independent and independent groups had equivalent dynamic sitting balance ability, it seems that the former method merits further investigation, even though it would mean each patient's dynamic sitting balance would need to be evaluated. One potential solution to the latter approach is the use of Chinese-style children's trousers (opencrotch pants) ${ }^{19)}$, which allow the wearer to defecate simply by sitting down. As these pants obviate the need to pull up and down or remove clothing they make toileting easy, but they also present problems, including the fact that they leave the buttocks constantly exposed. It seems be unfeasible to employ them in their existing form for hemiplegic patients. However, we consider that taking the design of these pants as a reference point, and adapting them to suit hemiplegic patients, could improve the ability of hemiplegic patients with poor standing balance to pull the lower garments up and down.

A limitation of this study is that only a small number of patients were surveyed, and there were therefore imbalances between the independent and non-independent groups in terms of gender and side of stroke. In the future we will need to verify the results using a larger sample.

\section{REFERENCES}

1) Yu LC, Kaltreider DL, Hu T, et al.: The ISQ-P tool: measuring stress associated with incontinence. J Gerontol Nurs, 1989, 15: 9-15. [Medline] [CrossRef]

2) Sakurai H, Tsujimura T, Sugiura $Y$, et al.: Determinants of return to home after stroke: an analysis based on FIM scores. J Phys Ther Sci, 2011, 23: 283-287. [CrossRef]

3) Okuno Y, Miyasaka T, Dobashi K: Factors influencing the outcome of acute rehabilitation: functional independence measure assessment at discharge. J Phys Ther Sci, 2012, 24: 491-494. [CrossRef]

4) Sakurai H, Sugiura $Y$, Sigiura T, et al.: Determinants of return to home after stroke: an analysis based on families' views. J Phys Ther Sci, 2011, 23: 673-677. [CrossRef]

5) Keith RA, Granger CV, Hamilton BB, et al.: The Functional Independence Measure; A new Tool for Rehabilitation. Advances in clinical rehabilitation2, New York: Springer, 1987, pp 6-18.

6) Walker MF, Lincoln NB: Reacquisition of dressing skills after stroke. Int Disabil Stud, 1990, 12: 41-43. [Medline] [CrossRef]

7) Walker MF, Lincoln NB: Factors influencing dressing performance after stroke. J Neurol Neurosurg Psychiatry, 1991, 54: 699-701. [Medline] [CrossRef]

8) American Occupational Therapy Association: Occupational therapy practice framework: Domain \& process, 3rd ed. Am J Occup Ther, 2014, 68: S1-S48.

9) Fisher AG: Occupational therapy intervention process model: A model for planning and implementing top-down, client-centered, and occupationbased interventions. Fort Collins: Three Star Press, 2009.

10) Neistadt ME: Occupational Therapy Evaluation for Adults: A Pocket Guide. Baltimore: Lippincott Williams \& Wilkins, 2000.

11) Yokozuka M, Abe K, Konno K, et al.: Relationship between toilet activity and standing balance with hemiplegics. Rigakuryoho Kagaku, 2005, 20: 289-292 (in Japanese). [CrossRef]

12) Koike $Y$, Koeda S, Sumigawa K, et al.: Need for, and possibility of, training in seated dressing during toileting in stroke patients with poor standing balance. Igaku To Seibutsugaku, 2013, 157: 688-695. 
13) Koike $Y$, Koeda S, Sumigawa K, et al.: Improving toileting in stroke patients: a literature review. Igaku To Seibutsugaku, 2013, 157: 1017-1021 (in Japanese).

14) Brunnstrom S: Motor testing procedures in hemiplegia: based on sequential recovery stages. Phys Ther, 1966, 46: 357-375. [Medline]

15) Collin C, Wade D: Assessing motor impairment after stroke: a pilot reliability study. J Neurol Neurosurg Psychiatry, 1990, 53: 576-579. [Medline] [CrossRef]

16) Duncan PW, Weiner DK, Chandler J, et al.: Functional reach: a new clinical measure of balance. J Gerontol, 1990, 45: M192-M197. [Medline]
[CrossRef]

17) Tyson SF, DeSouza LH: Reliability and validity of functional balance tests post stroke. Clin Rehabil, 2004, 18: 916-923. [Medline] [CrossRef]

18) Gillen G: Stroke Rehabilitation: A Function-based Approach, 3rd ed. St Louis: Mosby, 2011, pp 716-734.

19) Ogiwara $\mathrm{H}$ : The facts of toilets training to children with and without developmental disabilities in China-comparison with Chengdu Sichuan China and Japan-. Nagoya Ryujo College, Annual Report of Studies, 2006, 26: 135-148 (in Japanese). 